\section{Medicina baseada em evidências}

Médico aposentado, leio menções a uma "Medicina Baseada em Evidências" (MBE), sem no entanto perceber qualquer maneira de distinguir as diferenças com as qualidades da medicina que aprendi na $\mathrm{Fa}$ culdade de Medicina e que utilizei e assisti no exercício da profissão.

Por esse motivo, licomatenção especial o artigo publicado na Revista da Associação Médica Brasileira, as páginas de 165 a I68do Volume 47, n², Abril/Junho 200 I, sob o título "Transferindo as evidências da pesquisa clínica para a prática cardiológica”.

Logo no início, a afirmação: "Esta mudança é a do modelo da decisão clínica segundo opiniões isoladamente, para o modelo da decisão baseada em evidências. Isto conduz a uma avaliação crítica sistemática, das informações disponíveis, para a prática da tomada de decisão clínica." Causou estranheza a caracterização do modelo da medicina clássica: "modelo da decisão clínicasegundo opiniões isoladamente", eo novo modelo, o da "decisão baseada em evidências" não me parece que seja "novo". A conduta do médico sempre foi e é baseada nas evidências disponíveis de seu conhecimento, dependentes de conhecimento e possibilidades técnicas da medicina de sua época.

Todaa argumentação do articulista não caracteriza o conceito de que a MBE seja uma medicina conceituada diferentemente do que éa medicina de hojee a do passado, baseada no conhecimento científico gerale no estado do relacionamento ético entre pessoas.

Particularmente rebarbativas, as afirmaçõesfeitas nas linhas 6a I I da página I 68: "O acesso ao conteúdo (itens que necessitam ser conhecidos) eao processo (comoaprender eaplicar os fatos) requer estiloe atitudes diferentes daquelas aprendidas nauniversidadee residência médicaanteriores", ea qualificação implícita daatividademédicaquenão aMBE nas linhas de 14 a 18 da mesma página 168:"Tendo estes princípios como base, podemos nos definir contra a seqüência da prática pseudo científica: memorizar, regurgitar egraciosamenteesquecer".

\section{Orestes Barini São Paulo - SP}

\section{Comentário do Autor}

CaroDr. Barini,

Agradecemosa oportunidade de esclarecer aspectos importantes. As bases e os objetivos da prática médica continuam os mesmos. Porém, novos métodos, novos conceitos enovas "ferramentas" surgeme devem ser usados criteriosamente, sem prejuízo aos fundamentos básicos da medicina. Assim, por exemplo, devemos saber auscultar um sopro cardíaco, mas dispomos da ecodoppler cardiografia para aprimorar a nossa avaliação. AMedicina Baseada em Evidências é uma destas novas "ferramentas". Como não utilizar a melhor evidência científica disponível para tratarmos adequa- damente nossos pacientes?

Como podemos confiar apenas em nossas convicções pessoais, crenças e "achismos", adquiridosao longo denossa trajetória de prática clínica, sem refletirmos se realmente estamos trazendo benefícios clinicamente relevantes para nossos pacientes?

Podemos ter a noção de que a medicina não mudou, porque esta assertiva nos agrada, além de ser conveniente para se ajustar à nossa falta de mudanças visando aprimoramento das condutas diagnósticas e terapêuticas. A Medicina Baseada em Evidências, significa a integração da habilidade clínica com a melhor evidência científica disponível, ou seja, fazer o correto, da maneira correta.

A forma de exercermos a medicina está mudando e a resistência para a modificação é o sintoma da necessidade da mudança. A prática clínica envolve atualização científica, a qual por intermédio de uma avaliação crítica sistematizada, permite identificarmos as melhores condutas clínicas, cirúrgicas e diagnósticas. Após a identificação, devemos incorporar as novas evidências para que - benefício possa chegar aos nossos pacientes, evitando assim de nos tornarmos insuficientes em nossa função básica que é a de proporcionarmos e mantermos a saúde durante nossa atividade médica.

Álvaro Avezum 